\title{
Swimming Speed and Metabolic Rate during Routine Swimming and Simulated Diel Vertical Migration of Sergestes similis in the Laboratory ${ }^{1}$
}

\author{
David L. Cowles ${ }^{2}$
}

\begin{abstract}
Sergestes similis (Hansen, 1903) is a common mesopelagic vertically migrating shrimp common in the temperate and subarctic North Pacific Ocean. The species is a diel vertical migrator, although it remains primarily above the oxygen minimum layer in regions such as off California where the layer is well developed. This shipboard study with a computer-controlled swim tunnel provided the first continuous examination of this species' swimming behavior and metabolism over a 24-hr cycle. Sergestes similis swam at a routine speed of around 4.4 to $4.95 \mathrm{~cm} \mathrm{sec}^{-1}$. Burst speeds ranged from 14 to $>20 \mathrm{~cm} \mathrm{sec}^{-1}$. Swimming speeds during the day, at low temperatures simulating those at daytime depths, were similar to those at night at the higher temperatures characteristic of the surface. Night metabolic rates were higher than in the day, especially during the early night when most feeding activity may take place. Swimming speeds during times of simulated vertical migration averaged slightly faster than those of routine day or night swimming, averaging $6.2 \mathrm{~cm} \mathrm{sec}-1$ during the time of upward migration and $5.4 \mathrm{~cm} \mathrm{sec}^{-1}$ during simulated downward migration, but the difference was not significant. Downward migration is not accomplished by passive sinking. Calculations based on observed swimming activities and metabolic rates indicate that vertical migration confers a clear metabolic energy savings to $S$. similis over remaining resident in surface waters, though this result may not be applicable to other vertical migrators and is likely moderated by decreased feeding opportunities at depth.
\end{abstract}

Diel vertical migration is a widespread phenomenon among midwater species, the adaptive value of which has generated considerable discussion since discovery of the phenomenon. Postulated adaptive values have included predator avoidance, optimal foraging strategies, horizontal dispersal, growth and fecundity effects, metabolic advantages of changes in temperature, niche segregation, avoidance of photo-damage, group selection effects, and various combinations of these

1 This research was supported by cruises funded by NSF grants OCE91-15551 and OCE94-1543 to J. J. Childress. Manuscript accepted 30 September 2000.

2 Department of Natural Sciences, Loma Linda University, Loma Linda, California 92350 (phone: 909-5584300 ext. 48903; fax: 909-478-4259; E-mail: dcowles@ns. llu.edu).

Pacific Science (2001), vol. 55, no. 3:215-226

(C) 2001 by University of Hawai'i Press

All rights reserved
(Kerfoot 1970, 1985, Lampert 1989, 1993, Bevelhimer and Adams 1993, Loose and Dawidowicz 1994). Most of these hypotheses can be grouped into two major categories: that vertical migration confers some sort of metabolic advantage, or that it serves to reduce mortality by some mechanism such as predator avoidance (Lampert 1993).

Sergestes similis (Hansen, 1903) is a mesopelagic vertically migrating penaeid shrimp found in abundance along the North Pacific coast from Japan to the Gulf of California, off Chile, and in the eastern South Atlantic (Butler 1980, Farfante and Kensley 1997). It inhabits primarily the region above the oxygen minimum layer (Figure 1). Daytime depths for the species off the Oregon and California coasts, where it is one of the most abundant midwater micronektonic species (Barham 1956, Genthe 1969, Pearcy and Forss 1969, Omori 1979), range from 200 to $650 \mathrm{~m}$, and nighttime depths range from 50 to $200 \mathrm{~m}$ (Pearcy and Forss 1966, Omori and 


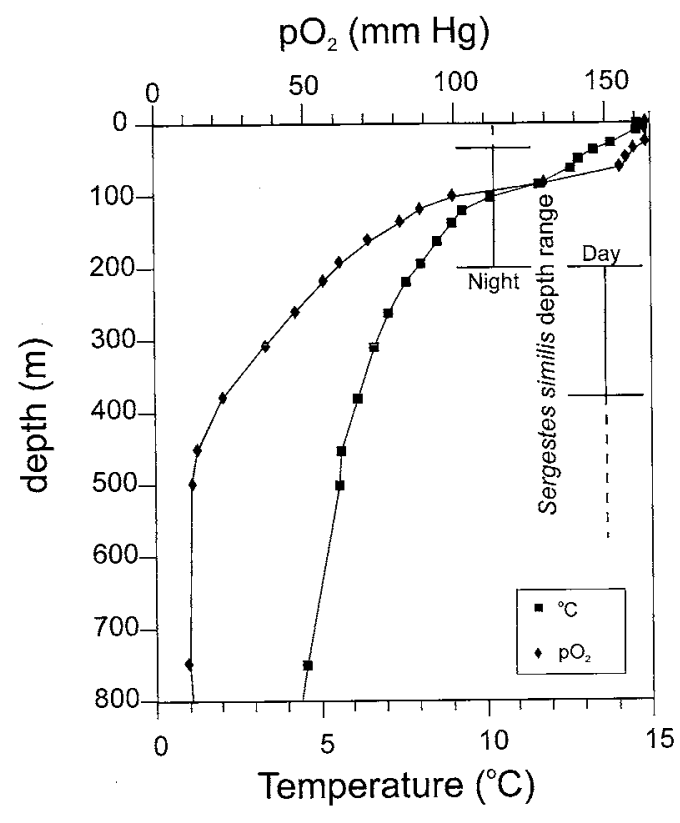

Figure 1. Depth distribution of Sergestes similis off California and Oregon, with vertical profiles of temperature and oxygen level. Error bars depict the day and night depth distributions reported in the literature. Solid bars indicate the depth range in which $80 \%$ of the population is found; dashed lines indicate the full reported depth range. See text for references. Temperature and oxygen profiles are from $32.05^{\circ} \mathrm{N}, 120.65^{\circ} \mathrm{W}$ in Rhines (1994). Depth distributions were extracted from Pearcy and Forss (1966), Omori and Gluck (1979), Schlining et al. (1997), and Childress (1975).

Gluck 1979, Schlining et al. 1997). Eighty percent of the population can be found between 10 and $400 \mathrm{~m}$ depths off California (Childress 1975).

As with most mesopelagic species, little is known about vertical migration in $S$. similis other than the range of depths in which it is found during the day and night. Information is scant, for example, about its behavior or activity levels at daytime and nighttime depths, on the costs and benefits of vertical migration to the species, or even whether downward migration is accomplished by active swimming or by passive sinking. Recent in situ studies of the species from a remotely operated vehicle (ROV) (Cowles 1994, Schlining et al. 1997) have elucidated some details of its swimming behavior, and methods have been developed that allow individuals to be captured in excellent condition for shipboard study (Childress et al. 1978). In this paper I report on the daily cycle of routine swimming activity, including simulated vertical migration, and on the species' routine rate of aerobic metabolism as measured in a shipboard swim tunnel simulating in situ conditions. I used these measurements to calculate the potential advantages and costs of vertical migration and used these to evaluate whether vertical migration confers some metabolic advantage on this species.

\section{MATERIALS AND METHODS}

Specimens of Sergestes similis were captured from midwater depths of 50 to $400 \mathrm{~m}$ off the coast of southern California by a midwater tucker trawl with a thermally insulating, opening and closing cod end (Childress et al. 1978). Trawling sites ranged from San Clemente Basin $\left(32.4^{\circ} \mathrm{N}\right)$ to Point Conception $\left(34.3^{\circ} \mathrm{N}\right)$. Active individuals, uninjured except for the loss of their long second antennae, were selected for use in experiments. These individuals were transferred immediately to 1-liter containers and held individually at $5-7^{\circ} \mathrm{C}$ on board ship until use. Subjects were held in continuous near-darkness except for occasional periods of incandescent lighting when the room was entered for animal maintenance.

The swim tunnel (Cowles et al. 1986, Cowles and Childress 1988) was a closed, recirculating system (Figure 2). Total water volume was 4.2 liters. In the tunnel, seawater was pumped into a flow collimator, then into the cylindrical swim chamber $35 \mathrm{~cm}$ long by $10.16 \mathrm{~cm}$ diameter), then through a heat exchanger, and back to the pump. The subject animal was tethered to a stainless steel torsion needle that was mounted vertically in the middle of the swim chamber but was able to tilt freely forward or backward. Tethering was by means of a 10-mg stainless steel loop fastened to the subject's rostrum by cyanoacrylate glue. The tethered animal was able to swim freely and to tilt up and down and from side to side, but it could not turn around backward in the tunnel. During an experiment, the animal swam forward in the tunnel 


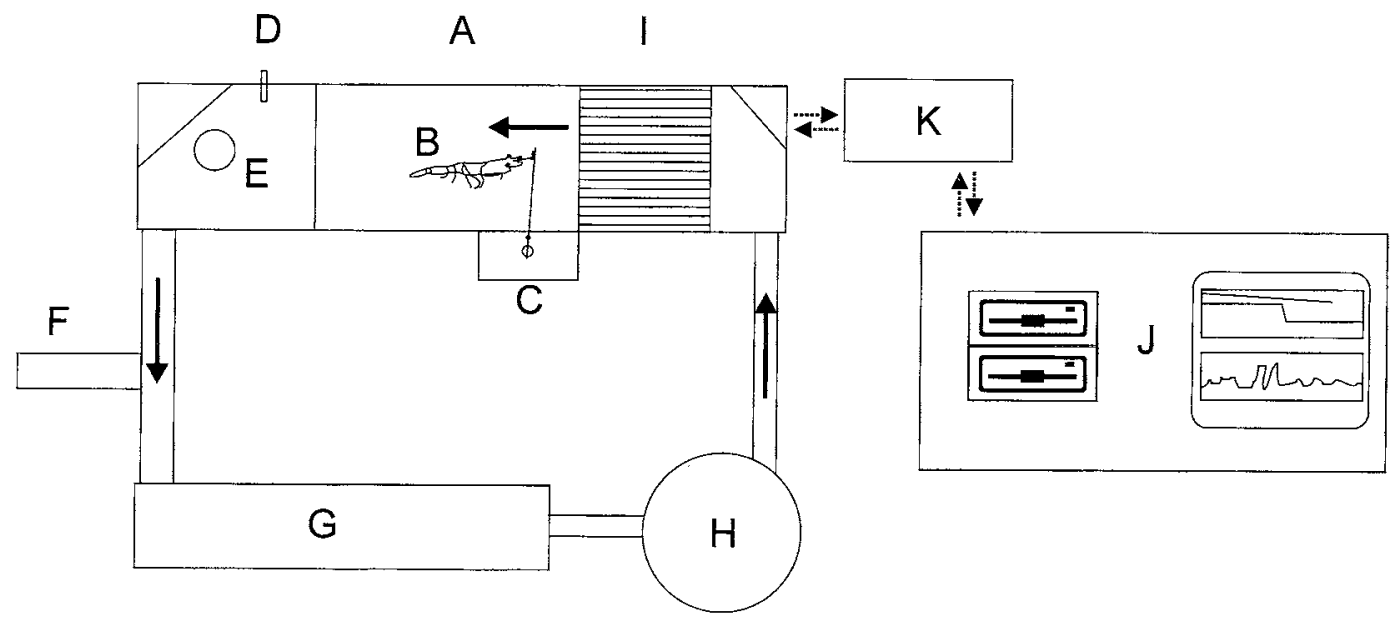

FIGURE 2. Schematic diagram of the computer-controlled swim tunnel used in this study: A, swim chamber; B, subject; C, tilt sensor; D, temperature probe; E, oxygen probe; F, flowmeter; $G$, heat exchanger; $H$, centrifugal pump; I, flow collimator; J, computer; $\mathrm{K}$, analog/digital interface between computer and instruments. Solid and dashed arrows show direction of water and information flow, respectively.

at whatever speed and body angle it chose, and the computer used the output from a tilt sensor (Spectron L-211u) mounted on the underside of the torsion needle to match the animal's speed continuously so that the subject remained stationary in the swim chamber regardless of the speed it swam. Oxygen levels within the chamber were measured with a polarographic, temperature-compensated, oxygen-regenerating oxygen electrode (Nester Instruments $8500 \mathrm{X}$ ), swimming speed was recorded by a magnetic flowmeter (Signet Mighty-Mag MK565), and temperature was recorded by a thermistor. All instrument output was monitored continuously by computer, which logged the mean and standard deviation values for each parameter every minute. In addition, the computer adjusted the water bath temperature throughout the day so that water temperatures in the swim tunnel mirrored the temperatures encountered by $S$. similis in situ $\left(7^{\circ} \mathrm{C}\right.$ by day, $13^{\circ} \mathrm{C}$ at night). The computer gradually adjusted the water temperatures between these two temperatures over a half-hour period during times for vertical migration, starting at 0600 hours for downward migration and at 2000 hours for upward migration.
Before each experiment the swim tunnel was filled with $0.2 \mu \mathrm{m}$ filtered seawater, and $20 \mathrm{mg} /$ liter of penicillin and of streptomycin were added to inhibit bacterial respiration. After the temperature had stabilized the animal was introduced, the chamber was sealed, and the entire swim tunnel was covered with multiple layers of dark cloth to approximate the dim light experienced by the species in situ. The subject was then allowed to swim undisturbed for up to $30 \mathrm{hr}$ at whatever speeds it chose while the computer constantly matched the subject's swimming speed and recorded the data. The experiment was not disturbed unless the instruments indicated that the animal had detached from the torsion needle, in which case data logging was interrupted and the animal was reattached. If oxygen pressure dropped below $50 \mathrm{~mm} \mathrm{Hg}$ in the chamber the water was reoxygenated. The animal was not disturbed during this process.

Visual observations were made on swimming subjects at the beginning of each experiment and at any time that the chamber had to be uncovered. In addition, 10 individuals were observed swimming for prolonged periods in an uncovered chamber. General behavior as well as pleopod beat 
rates were recorded for these individuals. Finally, for one individual swimming undisturbed in the covered chamber, oxygen levels were decreased to those characteristic of the oxygen minimum zone, and the differences in the animal's swimming response were recorded. All subjects were weighed after the experiment using a shipboard precision balance system (Childress and Mickel 1980).

Before analysis the data were cleaned of records from at least the first half hour at the beginning of each experiment, near any time of disturbance, for time periods in which the sensors were not calibrated, and any records for which temperature was more than $1^{\circ}$ from the target temperature. In addition, oxygen data were not used for any period in which a bubble was found in the chamber or during which the oxygen level was being adjusted. The $10 \%$ trimmed mean was used for calculating average oxygen consumption.

Routine swimming speeds and massspecific rates of oxygen consumption $\left(\mathrm{MO}_{2}\right.$, $\mu$ moles $\mathrm{O}_{2} \mathrm{~g}^{-1} \mathrm{hr}^{-1}$ ) were compared as functions of animal size, temperature, and time of day. Periods of vertical migration (synchronized with the species' local time of migration and simulated by an appropriate change of temperature in the swim tunnel) were compared with the periods of nonmigration. Only the average values for each individual or time period were used in making comparisons to maintain independence of the data. Data were tested for normality and homoscedasticity and were $\log$ transformed before analysis if required. Rates were compared using analysis of variance and the Tukey- $b$ multiple-range test. Possible changes in swimming speeds during vertical migration between colder, deep waters and the warmer surface waters were tested for by regression analysis of swimming speed as a function of temperature during the periods of vertical migration. Differences at the 0.05 confidence level were deemed significant, and those at the 0.01 confidence level were highly significant.

\section{RESULTS}

A total of 23 individuals was tested, ranging in wet weight from 250 to $1120 \mathrm{mg}$, in carapace length from 10.0 to $16.3 \mathrm{~mm}$, and in total length from 3.70 to $5.70 \mathrm{~cm}$. These sizes correspond to individuals 1-2 yr old (Omori and Gluck 1979). Some individuals began swimming immediately upon being placed in the swim chamber. Others were initially quiescent but began steady swimming within a few minutes after the chamber was covered. Most individuals swam nearly continuously throughout the entire experiment with only brief pauses, if any. Some individuals paused occasionally for up to several minutes, and the chamber was sometimes uncovered to ascertain the behavior causing this. Typically these individuals were either hovering in the water, swimming steadily but with no forward component, or were grooming themselves with their pereiopods. These experiments were allowed to continue without further disturbance, and typically the subjects resumed forward motion after a few minutes. Subjects did not show signs of fatigue during the experiments-no significant time-dependent changes in swimming speed were found.

Forward swimming was accomplished exclusively by use of the abdominal pleopods. The long thoracic pereiopods were usually held folded loosely against the ventral side of the thorax. However, individuals were frequently observed extending their pereiopods partially or fully while swimming, in which case their speed dropped sharply even though pleopod beat rate may not have changed. A number of individuals swam for extended periods with their pereiopods in the partly extended position. The usual swimming position was nearly horizontal, but if the chamber was uncovered and the subjects were exposed to light, many began to angle downward by deflecting their abdomen ventrally.

Pleopod beat rate ranged from 2.4 to $4.0 \mathrm{~Hz}$, with a mean of $3.2 \mathrm{~Hz}$. Pleopod beat rate at $13^{\circ} \mathrm{C}(3.4 \mathrm{~Hz})$ was only slightly higher than at $7^{\circ} \mathrm{C}(3.0 \mathrm{~Hz})$, but the difference was significant $(F=8.566 ; \mathrm{df}=1,8 ; P=0.019)$. Individuals $\leq 600 \mathrm{mg}$ wet weight had a slightly higher mean pleopod beat rate $(3.2 \mathrm{~Hz})$ than did larger individuals $(3.1 \mathrm{~Hz})$, but the difference was not significant $(F=$ $3.38 ; \mathrm{df}=1,8 ; P=0.103)$. Routine swimming speed was remarkably constant, averaging 


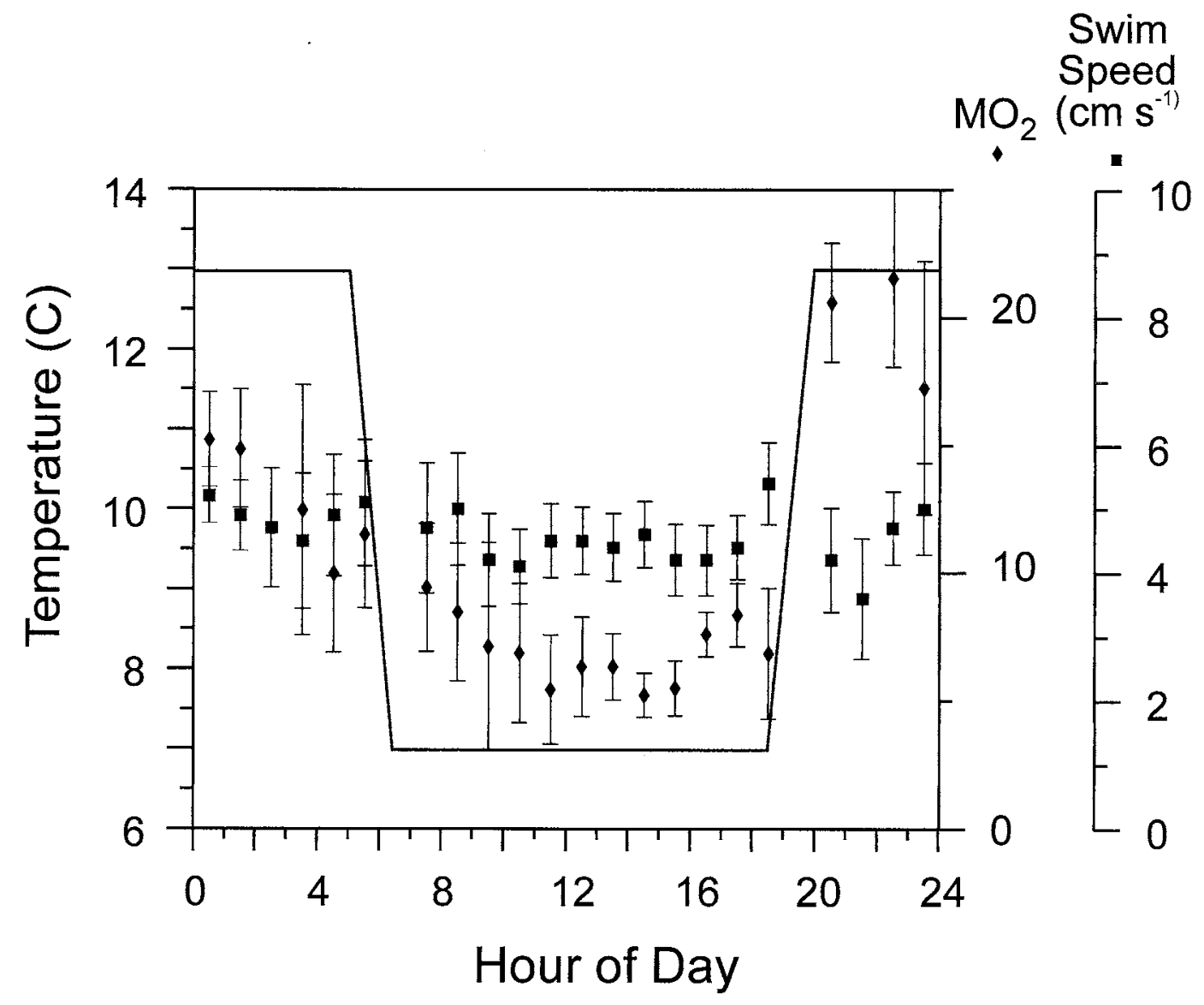

FIgURE 3. Average swimming speeds $(\mathrm{cm} / \mathrm{sec})$ and rates of aerobic metabolism ( $\mu$ moles $\mathrm{O}_{2} \mathrm{~g}^{-1} \mathrm{hr}^{-1}$ ) of Sergestes similis over $24 \mathrm{hr}$, as measured in this experiment. The cycling of water temperatures between day and night is shown by the solid line. Error bars for swimming speed and $\mathrm{MO}_{2}$ are standard error.

$4.6 \mathrm{~cm} \mathrm{sec}^{-1}$ (Figure 3). Neither temperature, wet weight, nor time of day had any significant effect on swimming speed. Aerobic metabolism, on the other hand, more than doubled in the warm $13^{\circ} \mathrm{C}$ temperatures characteristic of night depths $(F=13.47$; $\mathrm{df}=1,19 ; \quad P=0.002)$, though swimming speed during that time period was not significantly elevated $(F=0.397 ; \mathrm{df}=1,33$; $P=0.533$; Table 1). Wet weight had no significant effect on mass-specific metabolic rate over the limited range of sizes tested ( $F=0.24 ; \mathrm{df}=1,19 ; \quad P=0.63$ ). Together, these results indicate that temperature strongly affects metabolic rate but not pleo- pod beat rate or swimming speed, and that size has no consistent effect on metabolism or swimming speed, at least over the limited range of sizes studied. Therefore data from individuals of all sizes were pooled for subsequent analyses.

Hourly records of swimming speed and $\mathrm{MO}_{2}$ revealed that the highest rates of metabolism occurred in the evening in the hours just after dusk, when the subjects in situ would have just reached the shallow depths and have commenced feeding (Table 1, Figure 3). This elevated metabolism was not associated with any increase in swimming speed (Table 1), indicating that the higher metabo- 
TABLE 1

Changes in Sergestes similis Routine Swimming Speed $\left(\mathrm{cm} \mathrm{sec}^{-1}\right)$ and Body Lengths $\left(\mathrm{sec}^{-1}\right)$, Pleopod Beat Rate (Hz), and Aerobic Metabolism $\left(\mathrm{MO}_{2}, \mu\right.$ moles $\left.\mathrm{O}_{2} \mathrm{~g}^{-1} \mathrm{hr}^{-1}\right)$ with Temperature and Time of Day

\begin{tabular}{|c|c|c|c|c|c|c|c|c|c|c|c|c|}
\hline \multirow[b]{3}{*}{ Parameter } & \multicolumn{6}{|c|}{ Day, $7^{\circ} \mathrm{C}$} & \multicolumn{6}{|c|}{ Night, $13^{\circ} \mathrm{C}$} \\
\hline & \multicolumn{2}{|c|}{ Overall } & \multicolumn{2}{|c|}{$\begin{array}{l}\text { Dawn to } \\
\text { Noon }\end{array}$} & \multicolumn{2}{|c|}{$\begin{array}{l}\text { Noon to } \\
\text { Dusk }\end{array}$} & \multicolumn{2}{|c|}{ Overall } & \multicolumn{2}{|c|}{$\begin{array}{l}\text { Dusk to } \\
\text { Midnight }\end{array}$} & \multicolumn{2}{|c|}{$\begin{array}{l}\text { Midnight to } \\
\text { Dawn }\end{array}$} \\
\hline & Mean & $\mathrm{SE}(n)$ & Mean & $\mathrm{SE}(n)$ & Mean & SE $(n)$ & Mean & $\operatorname{SE}(n)$ & Mean & $\mathrm{SE}(n)$ & Mean & $\mathrm{SE}(n)$ \\
\hline $\begin{array}{l}\text { Spjeed } \\
\mathrm{cm} \mathrm{sec}{ }^{-1}\end{array}$ & 4.40 & $\begin{array}{l}0.47 \\
(23) \\
\end{array}$ & 4.58 & $\begin{array}{l}0.52 \\
(19) \\
\end{array}$ & 4.55 & $\begin{array}{l}0.47 \\
(20) \\
\end{array}$ & 4.95 & $\begin{array}{l}0.71 \\
(13) \\
\end{array}$ & 4.91 & $\begin{array}{l}0.60 \\
(15)\end{array}$ & 5.31 & $\begin{array}{l}0.66 \\
(16)\end{array}$ \\
\hline Length $\sec ^{-1}$ & 0.92 & $\begin{array}{l}0.10 \\
(23)\end{array}$ & 0.99 & $\begin{array}{l}0.11 \\
(19)\end{array}$ & 0.96 & $\begin{array}{l}0.10 \\
(20)\end{array}$ & 1.04 & $\begin{array}{l}0.14 \\
(13)\end{array}$ & 1.00 & $\begin{array}{l}0.12 \\
(15) \\
\end{array}$ & 1.09 & $\begin{array}{l}0.14 \\
(16)\end{array}$ \\
\hline Beat $\mathrm{Hz}$ & 3.01 & $\begin{array}{c}0.08 \\
(6)\end{array}$ & & & & & 3.41 & $\begin{array}{c}0.12 \\
(4)\end{array}$ & & & & \\
\hline $\mathrm{MO}_{2}$ & 7.15 & $\begin{array}{l}1.26 \\
(12)\end{array}$ & 8.08 & $\begin{array}{l}1.84 \\
(11)\end{array}$ & 6.42 & $\begin{array}{l}1.03 \\
(11)\end{array}$ & 17.45 & $\begin{array}{l}2.95 \\
(9)\end{array}$ & 22.44 & $\begin{array}{c}3.53 \\
(9)\end{array}$ & 17.07 & $\begin{array}{c}5.28 \\
(8)\end{array}$ \\
\hline
\end{tabular}

SE, standard error; $n$, the number of animals analyzed. Breaks in heavy bars indicate significant differences among groups.

lism was more closely associated with something other than swimming speed per se. Metabolic rate was also not strongly associated with swimming speed at either $7^{\circ} \mathrm{C}$ or $13^{\circ} \mathrm{C}$ (Figure 4). Indeed, the highest metabolic rates were consistently found at speeds slightly below the average speed. Plotting the change in metabolic rate with speed for individual animals (Figure 4) showed that this effect was a real one, at least for some animals. A number of individual animals had lower metabolic rates at low and high speeds, with a peak in metabolic rate at speeds of around 2$4 \mathrm{~cm} \mathrm{sec}^{-1}$. Others had a more conventional pattern of increasing metabolic rate with swimming speed and did not exhibit the high peak of metabolism at intermediate speeds. Within the range of oxygen partial pressures tested (>50 $\mathrm{mm} \mathrm{Hg}$ ), there was no relationship between oxygen pressure and either swimming speed or metabolic rate.

Although instantaneous speeds varied widely and continuously during each experiment (Figure 5), most individuals maintained a fairly constant average speed during any particular period of the day. Some individuals made occasional brief pauses, however, and most swam at speeds noticeably faster than
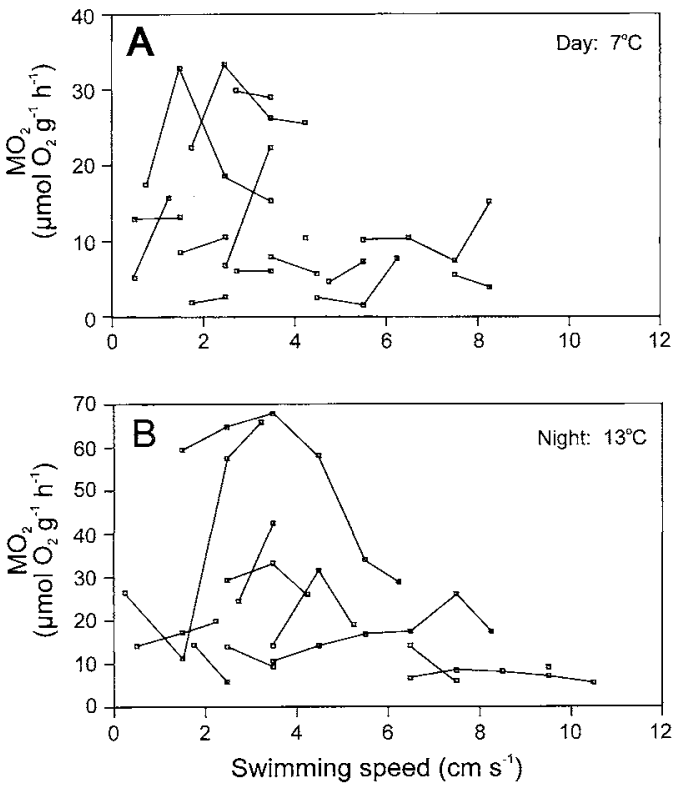

Figure 4. Aerobic metabolism $\left(\mathrm{MO}_{2}\right)$ as a function of swimming speed for Sergestes similis. A, During the day $\left(7^{\circ} \mathrm{C}\right) ; B$, during the night $\left(13^{\circ} \mathrm{C}\right)$. Lines connect points for the same individual. Note the elevated metabolic rates at speeds of around $2-4 \mathrm{~cm} \mathrm{sec}^{-1}$. 


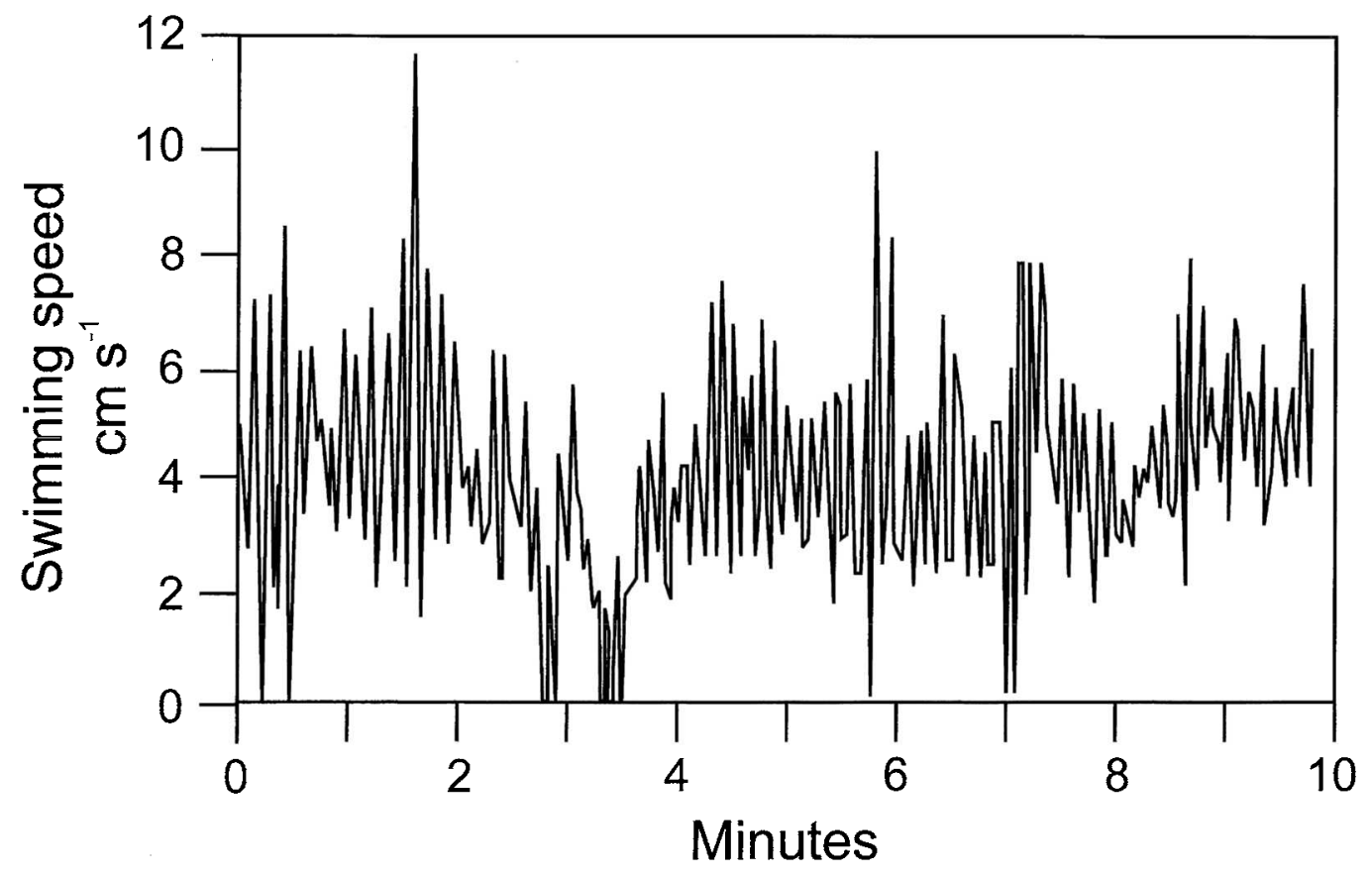

FIGURE 5. Variations in swimming speed over a 10-min period for one animal, showing a typical range and pattern of variations in speed.

their average speed during some part of the day. For most individuals the fastest minute of swimming was less than $10 \mathrm{~cm} \mathrm{sec}^{-1}$, and the fastest 1-min average speed recorded was $12.9 \mathrm{~cm} \mathrm{sec}^{-1}$. One-second burst speeds were even faster, and averaged around 14$20 \mathrm{~cm} \mathrm{sec}^{-1}$. The fastest $1-\mathrm{sec}$ burst speed recorded was $29.7 \mathrm{~cm} \mathrm{sec}^{-1}$. Some individuals also performed tail flips occasionally. When this happened, the computer stopped water flow immediately and waited a few seconds until the subject resumed forward motion. Most tail flips occurred when the subject was disturbed during the setup or end of an experiment, and therefore were excluded from analysis.

Swimming speeds during times of dawn and dusk vertical migrations were 1-2 $\mathrm{cm} \mathrm{sec}^{-1}$ higher than those of the rest of the day (Table 2), but the difference was not significant $(F=2.53$; df $=1,32 ; P=0.12)$. Sixteen of 17 individuals swam as fast or significantly faster during times of vertical

\section{TABLF 2}

Swimming Speeds ( $\mathrm{cm} \mathrm{sec}^{-1}$ ) during Upward (Dusk) and Downward (Dawn) Vertical Migrations as Compared with Times of No Migration

\begin{tabular}{lcll}
\hline \hline Direction & Mean Speed & $\mathrm{SE}^{a}$ & $n$ \\
\hline No vertical migration & 4.6 & 0.4 & 25 \\
Upward (dusk) & 6.2 & 0.26 & 12 \\
Downward (dawn) & 5.4 & 0.4 & 10 \\
All vertical migration & 5.9 & 0.5 & 17 \\
\hline
\end{tabular}

a Standard error.

migration than they did at other times of day. Upward migration speed $\left(6.2 \mathrm{~cm} \mathrm{sec}^{-1}\right)$ averaged higher than downward speed (5.4 $\mathrm{cm} \mathrm{sec}-1)$, but the difference was not significant $(F=0.59 ; \mathrm{df}=1,20 ; P=0.45)$. During vertical migration, there was no significant correlation between temperature and swimming speed. Metabolic rate could not be measured reliably during vertical migration because of rapid changes in temperature. 


\section{DISCUSSION}

These experiments provided a model rather than a precise match for the in situ conditions experienced by $S$. similis. Though restraint on subjects, for example, was kept to a minimum so that they could turn left, right, up, or down and vary their speed at will, they were not swimming completely freely in the water. They could not turn around backward, and active swimming was only accommodated in a forward direction. Similarly, though light was kept to the low levels roughly characteristic of their environment, the dim light present in the tunnel was not downwelling, it was of broader spectrum than found in midwater, and it did not track the movement of the sun and moon in direction or in intensity. The effects of exposure to surface light levels and the loss of the subjects' second antennae during collection are also not known. Ambient pressure remained at 1 atmosphere (atm) throughout the experiment rather than changing with depth, and the animals could not sink straight down nor swim straight up. That being said, a number of lines of evidence suggest that the tunnel was able to replicate midwater conditions closely enough that the subjects' behavior in the tunnel was representative of their normal behavior. The mean and range of swimming speeds observed here, for example, are similar to those reported for this species in situ (Cowles 1994). The fact that the subjects swam steadily and apparently unperturbed for many hours in the tunnel with no time-dependent change in their performance suggests that they were performing routine behavior. During occasional pauses the animals engaged in the types of grooming behavior previously observed in midwater, suggesting unperturbed activity. Subjects in the tunnel also typically angled downward when exposed to light, as they do in midwater. Further, the fact that their behavior changed in regular and predictable ways throughout the daily cycle suggests that they were behaving in routine manners. Thus though the animals were not actually in midwater during the experiment, the replicated time frame, reduced light, substantial freedom of movement, and
TABLE 3

Rates of Aerobic Metabolism of Sergestes Species Reported in the Literature

\begin{tabular}{|c|c|c|}
\hline Species & $\begin{array}{l}\text { Aerobic Metabolism } \\
\left(\mu \text { moles } \mathrm{O}_{2} \mathrm{~g}^{-1} \mathrm{hr}^{-1}\right)\end{array}$ & Reference \\
\hline $\begin{array}{l}\text { Sergestes } \\
\text { similis }\end{array}$ & 12.3 & This paper \\
\hline S. similis & 3.09 to 3.87 & Childress (1975) \\
\hline S. similis & 12.6 & $\begin{array}{l}\text { Pearcy and Small } \\
\text { (1968) }\end{array}$ \\
\hline S. crassus & 5.58 & Teal (1971) \\
\hline S. arcticus & 3.03 & $\begin{array}{l}\text { Bailey et al. } \\
\text { (1995) }\end{array}$ \\
\hline S. armnatus & 5.69 & $\begin{array}{c}\text { Donnelly and } \\
\text { Torres } \\
(1988)\end{array}$ \\
\hline S. corniculum & 4.65 & $\begin{array}{l}\text { Donnelly and } \\
\text { Torres } \\
(1988)\end{array}$ \\
\hline
\end{tabular}

Note: Rates were corrected to $10^{\circ} \mathrm{C}$ using $Q_{10}$ data from the literature or a $Q_{10}$ of 2 if the actual $Q_{10}$ was not known. Dry weights were converted to wet weights using the ratio of $0.234 \mathrm{~g}$ dry wt/g wet wt (Childress and Nygaard 1974).

changes in water temperature simulating changes in depth appear to have created an environment similar enough to their normal environment to allow them to behave in a routine manner. Behavior in the swim tunnel thus provides a reasonable model of behavior in midwater and constitutes by far the longest and most complete records available of swimming characteristics for this species.

The routine rates of aerobic metabolism reported here are higher than most of the rates reported in the literature for Sergestes species, sometimes by as much as two to three times (Table 3). This is true for all speeds, but especially for the low to intermediate speeds at which individuals often had unusually high rates (Figure 4). This can be explained by a variety of factors that give additional insight into the biology of S. similis and provide a caution for interpreting measurements of routine metabolism. First, previous studies have measured routine metabolism in an enclosed chamber in which the subject was not free to swim about as it normally would. The opportunity to swim about, as in this study, likely resulted in higher overall routine activity and elevated 
TABLE 4

Estimation of Daily Calorie Expenditures by a Vertically Migrating Sergestes similis

\begin{tabular}{llccrrr}
\hline \hline Period & ${ }^{\circ} \mathrm{C}$ & $\begin{array}{c}\text { Swim Speed } \\
\left(\mathrm{cm} \mathrm{sec}^{-1}\right)\end{array}$ & $\begin{array}{c}\mathrm{MO}_{2} \\
\left(\mu \text { moles } \mathrm{O}_{2} \mathrm{~g}^{-1} \mathrm{hr}^{-1}\right)\end{array}$ & $\mathrm{Hr}:$ Min & $\begin{array}{c}\text { Total } \\
\mu \text { moles } \mathrm{O}_{2} / \mathrm{g}\end{array}$ & $\begin{array}{c}\text { Total } \\
\text { calories/g }\end{array}$ \\
\hline Day (at depth) & 7 & 4.40 & 7.15 & $12: 12$ & 87.23 & 9.38 \\
Upward migration & $7-13$ & 6.20 & 11.17 & $1: 34$ & 17.50 & 1.88 \\
Night (near surface) & 13 & 4.95 & 17.45 & $8: 26$ & 147.16 & 15.82 \\
Downward migration & $13-7$ & 5.40 & 11.17 & $1: 48$ & 20.11 & 2.16 \\
$\quad$ Total & & & & $24: 00$ & 272.0 & 29.24 \\
\hline
\end{tabular}

Note: $\mathrm{Hr}:$ Min, the amount of time (hours : minutes) spent in the activity assuming vertical migration is accomplished in $350 \mathrm{~m}$ of swimming. Metabolic rate during vertical migration is calculated at $10^{\circ} \mathrm{C}$ by the $\mathrm{Q}_{10}$ method based on metabolic rates at $7^{\circ} \mathrm{C}$ and $13^{\circ} \mathrm{C}$.

metabolism over that measured in most previous studies. The higher metabolic rate reported here is likely closer to the species' true routine metabolism because the conditions are more similar to those in situ. The lower rates reported earlier represent metabolism under restricted activity and likely fall between true routine metabolism and standard metabolism. The same effect was observed in another midwater species, the bathypelagic mysid Gnatbophausia ingens (Cowles and Childress 1988). Indeed, the routine rates reported here are also likely to be underestimates of the in situ rate of routine metabolism because the animal swimming in situ would experience additional drag from its trailing second antennae. On the other hand, it is unlikely that the restriction to horizontal swimming in this experiment had a large effect on animal metabolism because this species is only slightly negatively buoyant (Childress and Nygaard 1974). The energy expended while angling upward or downward through the water column should therefore be little different from that expended while swimming horizontally. Similarly, testing at $1 \mathrm{~atm}$ pressure is unlikely to have had a large effect on the data because Pearcy and Small (1968) found no significant effect of pressure on metabolism in this species.

The elevated rates of metabolism often observed at low and intermediate speeds (Figure 4) are likely due to several additional sources of drag and provide further insights about the biology of this species. First, subjects swimming at low speeds swam at an oblique angle (head upward) to the oncoming water, a phenomenon also documented for G. ingens (Cowles et al. 1986) and attributed to the species' slight negative buoyancy. The more slowly the animal swam the more oblique the angle. This posture produces increased drag and leads to higher metabolism than expected in swimming crustaceans, especially in those swimming slowly (Cowles and Childress 1988). More important, the frequent partial or full extension of the pereiopods would result in increased drag, slower swimming speeds, and an elevated metabolic rate. Increase in drag associated with changes in posture, especially the extension of the pereiopods that occurs at intermediate speeds, therefore seems to have a greater effect on metabolic rate than does swimming speed per se (Figure 4). In these experiments, slow swimming seemed to result primarily from increased drag due to swimming at an oblique angle and to extension of the pereiopods rather than from simply swimming less vigorously, as seen from the low correlation between swimming speed and pleopod beat rate. In that regard it is also interesting to note that the early nighttime period, when the most intensive feeding behavior is likely to be taking place, was the period in which the highest metabolic rates occurred, although swimming speeds during that time are slightly lower than those observed later in the night. This is consistent with the spreading of the pereiopods as a feeding posture early in the night. It should be noted, however, that the same peak in metabolic rates was seen in some individuals swimming at low and intermediate speeds during the day at $7^{\circ} \mathrm{C}$ (Figure 
$4 A$ ), which implies that $S$. similis may feed at depth during the day as well as near the surface at night. Daytime sergestid feeding at depth has also been reported by Omori (1969), Judkins and Fleminger (1972), Donaldson (1975), and Walters (1976).

Vertical migration has been postulated as an energy-saving mechanism for poikilothermic migrators (McLaren 1963, 1974, Brett 1971, Levy 1987, Bevelhimer and Adams 1993). According to this hypothesis, vertical migrators feed in the warm, food-rich upper layers and then drop down to the cooler water below to rest and digest their food. The cooler temperature depresses their metabolism, allowing them to allocate a greater portion of their caloric intake to growth and reproduction. Further savings could potentially be obtained by a passive sinking of the migrator during downward migration. This study provided a unique opportunity to examine this hypothesis using actual metabolic measurements of a vertical migrator over a full daily cycle. Using an oxycalorific equivalent of 4.8 kilocalories/liter of oxygen (Gordon 1977), assuming for simplicity that the species swims almost directly upward or downward during migrations and accomplishes a 300-m vertical depth change with only $350 \mathrm{~m}$ of swimming, and assuming that $\mathrm{MO}_{2}$ during vertical migration is midway between that characteristic of the warm water above and the cold water below, a vertically migrating $S$. similis would metabolize about 29 calories per gram per day (Table 4). In contrast, daily metabolism would be 45 calories if it remained in surface waters and 18 calories if it remained at depth. Vertical migration does, then, result in clear metabolic energy savings for this species when compared with the cost of staying near the surface, which is consistent with the energysavings hypothesis. Whether this energy savings offsets the lost opportunities for feeding in surface layers is unknown. The elevated metabolic rates seen in some individuals at $2-4 \mathrm{~cm} \mathrm{sec}^{-1}$ during the day suggest that some feeding may take place even at depth, as reported elsewhere for this species (Omori 1969, Judkins and Fleminger 1972, Donaldson 1975, Walters 1976). On the other hand, the increased cost of vertical migration over that of staying at depth must be offset by the greater availability of food near the surface, at least for most of the population.

Several features of $S$. similis migration have an important effect on these energy calculations. This species is equally active throughout the day and night and does not become quiescent at depth as is often assumed by the energy-saving hypothesis for vertical migration. Downward migration is not accomplished by passive sinking; indeed, mean swimming speeds during downward migration were faster than those during routine daily activity and were exceeded only by speeds during times of upward migration. Both of these factors tend to decrease the energy benefit of vertical migration. On the other hand, vertical migration seems to entail only a slight increase in activity over routine levels, at least in this species. This would tend to increase the energetic benefit by decreasing the net cost of migration. Further, though these calculations for $S$. similis show a decrease in daily metabolic costs over remaining at the surface, they do not account for other costs that may be involved such as lost feeding opportunities and retarded development during residence in the colder deep waters. Although these daily energy budgets cannot rule out energetic savings as the adaptive advantage driving vertical migration in this species, more information must be obtained before either energy savings or predator avoidance can be definitively identified as the primary adaptive value of this behavior.

\section{ACKNOWLEDGMENTS}

My thanks to the crews of the R.V. New Horizon and Point Sur, and to James J. Childress, Erik V. Thuesen, Karen Light, and the Monterey Bay Aquarium for providing research space on cruises, and to the anonymous reviewers for comments on the manuscript.

\section{Literature Cited}

Bailey, T. G., M. J. Youngbluth, and G. P. Owen. 1995. Chemical composition and 
metabolic rates of gelatinous zooplankton from midwater and benthic boundary layer environments off Cape Hatteras, North Carolina, USA. Mar. Ecol. Prog. Ser. 122:121-134.

Barham, E. G. 1956. The ecology of sonic scattering layers in the Monterey Bay area. Ph.D. diss., Stanford University, Palo Alto, California.

Bevelhimer, M. S., and S. M. Adams. 1993. A bioenergetics analysis of diel vertical migration by Kokanee salmon, Oncorbynchus nerka. Can. J. Fish. Aquat. Sci. 50:23362349.

Brett, J. R. 1971. Energetic responses of salmon to temperature: A study of some thermal relations in the physiology and freshwater ecology of sockeye salmon (Oncorbyncbus nerka). Am. Zool. 11:99113.

Butler, T. H. 1980. Shrimps of the Pacific coast of Canada. Can. Bull. Fish. Aquat. Sci. 202:1-280.

Childress, J. J. 1975. The respiratory rates of midwater crustaceans as a function of depth of occurrence and relation to the oxygen minimum layer off southern $\mathrm{Cali}-$ fornia. Comp. Biochem. Physiol. A Comp. Physiol. 50:787-799.

Childress, J. J., and T. J. Mickel. 1980. A motion-compensated shipboard precision balance system. Deep-Sea Res. Part A. Oceanogr. Res. Pap. 27:965-970.

Childress, J. J., and M. Nygaard. 1974. Chemical composition and buoyancy of midwater crustaceans as function of depth of occurrence off southern California. Mar. Biol. (Berl.) 27:225-238.

Childress, J. J., A. T. Barnes, L. B. Quetin, and B. H. Robison. 1978. Thermally protecting cod ends for the recovery of living deep sea animals. Deep-Sea Res. 25:419422.

Cowles, D. L. 1994. Swimming dynamics of the mesopelagic vertically migrating penaeid shrimp Sergestes similis: Modes and speeds of swimming. J. Crustacean Biol. 14:247-257.

Cowles, D. L., and J. J. Childress. 1988. Swimming speed and oxygen consumption in the bathypelagic mysid Gnatbopbausia ingens. Biol. Bull. (Woods Hole) 175:111121.

Cowles, D. L., J. J. Childress, and D. L. Gluck. 1986. New method reveals unexpected relationship between velocity and drag in the bathypelagic mysid Gnatbophausia ingens. Deep-Sea Res. Part A. Oceanogr. Res. Pap. 33:865-880.

Donaldson, H. A. 1975. Vertical distribution and feeding of sergestid shrimps (Decapoda: Natantia) collected near Bermuda. Mar. Biol. (Berl.) 31:37-50.

Donnelly, J., and J. J. Torres. 1988. Oxygen consumption of midwater fishes and crustaceans from the eastern Gulf of Mexico. Mar. Biol. (Berl.) 97:483-494.

Farfante, I. P., and B. Kensley. 1997. Penaeoid and sergestoid shrimps and prawns of the world. Mem. Mus. Natl. Hist. Nat. Ser. A Zool. 175.

Genthe, H. C., Jr. 1969. The reproductive biology of Sergestes similis (Decapoda: Natantia). Mar. Biol. (Berl.) 2:203-217.

Gordon, M. S. 1977. Animal physiology: Principles and adaptations. Macmillan, New York.

Hansen, H. J. 1903. On the crustaceans of the genera Petalidium and Sergestes from the Challenger, with an account of the luminous organs in Sergestes challengeri, n.sp. Proc. Zool. Soc. Lond. 1:52-79.

Judkins, D. C., and A. Fleminger. 1972. Comparison of foregut contents of Sergestes similis obtained from net collections and albacore stomachs. Fish. Bull. 70:217-223.

Kerfoot, W. C. 1970. Bioenergetics of vertical migration. Am. Nat. 104:529-546.

- 1985. Adaptive value of vertical migration: Comments on the predation hypothesis and some alternatives. Pages 91-113 in M. A. Rankin, ed. Migration: Mechanisms and adaptive significance. Contrib. Mar. Sci. Suppl. 27.

Lampert, W. 1989. The adaptive significance of vertical migration of zooplankton. Funct. Ecol. 3:21-27.

. 1993. Ultimate causes of diel vertical migration of zooplankton: New evidence for the predator-avoidance hypothesis. Arch. Hydrobiol. Beih. 39:79-88.

Levy, D. A. 1987. Review of the ecological 
significance of diel vertical migrations by juvenile sockeye salmon (Oncorbynchus nerka). Can. Spec. Publ. Fish. Aquat. Sci. 96:44-52.

Loose, C. J., and P. Dawidowicz. 1994. Trade-offs in diel vertical migration by zooplankton: The costs of predator avoidance. Ecology 75:2255-2263.

McLaren, I. A. 1963. Effects of temperature on growth of zooplankton, and the adaptive values of vertical migration. J. Fish. Res. Board Can. 20:685-727.

1974. Demographic strategy of vertical migration by a marine copepod. Am. Nat. 108:91-102.

Omori, M. 1969. The biology of a sergestid shrimp Sergestes lucens Hansen. Bull. Ocean Res. Inst. Univ. Tokyo 4:1-83. 1979. Growth, feeding, and mortality of larval and early postlarval stages of the oceanic shrimp Sergestes similis Hansen. Limnol. Oceanogr. 24:273-288.

Omori, M., and D. Gluck. 1979. Life history and vertical migration of the pelagic shrimp Sergestes similis off the southern California coast. Fish. Bull. 77:183-198.
Pearcy, W. G., and C. A. Forss. 1966. Depth distribution of oceanic shrimps (Decapoda: Natantia) off Oregon. J. Fish. Res. Board Can. 23:1135-1143. 1969. The oceanic shrimp Sergestes similis off the Oregon coast. Limnol. Oceanogr. 14:755-765.

Pearcy, W. G., and L. F. Small. 1968. Effects of pressure on the respiration of vertically migrating crustaceans. J. Fish. Res. Board Can. 25:1311-1316.

Rhines, P. B. 1994. ATLAST: A world-ocean atlas of hydrography, nutrients, and chemical tracers. Univ. Wash. School Oceanogr. Tech. Rep. 91-1, release 3.51.

Schlining, B. M., B. H. Robison, and K. R. Reisenbichler. 1997. Midwater observations using the ROV Ventana (abstract). Page 101 in 8th Deep-Sea Biology Symposium, Monterey, California.

Teal, J. M. 1971. Pressure effects on the respiration of vertically migrating decapod crustacea. Am. Zool. 11:571-576.

Walters, J. F. 1976. Ecology of Hawaiian sergestid shrimps (Penaeidea: Sergestidae). Fish. Bull. 74:799-836. 